\title{
Maladaptive aortic properties after the Norwood procedure: An angiographic analysis of the Pediatric Heart Network Single Ventricle Reconstruction Trial
}

\author{
Sarah T. Plummer, MD, ${ }^{\mathrm{a}}$ Christoph P. Hornik, MD, MPH, ${ }^{\mathrm{a}}$ Hamilton Baker, MD, ${ }^{\mathrm{b}}$ \\ Gregory A. Fleming, MD, MS, ${ }^{\mathrm{a}}$ Susan Foerster, MD, ${ }^{\mathrm{c}} \mathrm{M}$. Eric Ferguson, MD, ${ }^{\mathrm{d}}$ \\ Andrew C. Glatz, MD, MSCE, ${ }^{\mathrm{e}}$ Russel Hirsch, MD, ${ }^{\mathrm{f}}$ Jeffrey P. Jacobs, MD, ${ }^{\mathrm{g}}$ Kyong-Jin Lee, MD, \\ Alan B. Lewis, MD, ${ }^{i}$ Jennifer S. Li, MD, MS, ${ }^{a}$ Mary Martin, MD, ${ }^{j}$ Diego Porras, MD, \\ Wolfgang A. K. Radtke, MD, ${ }^{\mathrm{k}}$ John F. Rhodes, MD, ${ }^{\mathrm{m}}$ Julie A. Vincent, MD, ${ }^{\mathrm{n}}$ Jeffrey D. Zampi, MD, ${ }^{\circ}$ and \\ Kevin D. Hill, MD, MS
}

\begin{abstract}
Objectives: Aortic arch reconstruction in children with single ventricle lesions may predispose to circulatory inefficiency and maladaptive physiology leading to increased myocardial workload. We sought to describe neoaortic anatomy and physiology, risk factors for abnormalities, and impact on right ventricular function in patients with single right ventricle lesions after arch reconstruction.

Methods: Prestage II aortic angiograms from the Pediatric Heart Network Single Ventricle Reconstruction trial were analyzed to define arch geometry (Romanesque [normal], crenel [elongated], or gothic [angular]), indexed neoaortic dimensions, and distensibility. Comparisons were made with 50 single-ventricle controls without prior arch reconstruction. Factors associated with ascending neoaortic dilation, reduced distensibility, and decreased ventricular function on the 14-month echocardiogram were evaluated using univariate and multivariable logistic regression.
\end{abstract}

Results: Interpretable angiograms were available for 326 of 389 subjects (84\%). Compared with controls, study subjects more often demonstrated abnormal arch geometry $(67 \%$ vs $22 \%, P<.01)$ and had increased ascending neoaortic dilation $(Z$ score $3.8 \pm 2.2$ vs $2.6 \pm 2.0, P<.01)$ and reduced distensibility index $(2.2 \pm 1.9$ vs $8.0 \pm 3.8, P<.01)$. Adjusted odds of neoaortic dilation were increased in subjects with gothic arch geometry (odds ratio $[\mathrm{OR}], 3.2$ vs crenel geometry, $P<.01$ ) and a right ventricle-pulmonary artery shunt (OR, 3.4 vs Blalock-Taussig shunt, $P<.01)$ but were decreased in subjects with aortic atresia (OR, 0.7 vs stenosis, $P<.01$ ) and those with recoarctation (OR, 0.3 vs no recoarctation, $P=.04$ ). No demographic, anatomic, or surgical factors predicted reduced distensibility. Neither dilation nor distensibility predicted reduced right ventricular function.

Conclusions: After Norwood surgery, the reconstructed neoaorta demonstrates abnormal anatomy and physiology. Further study is needed to evaluate the longerterm impact of these features. (J Thorac Cardiovasc Surg 2016;152:471-9)

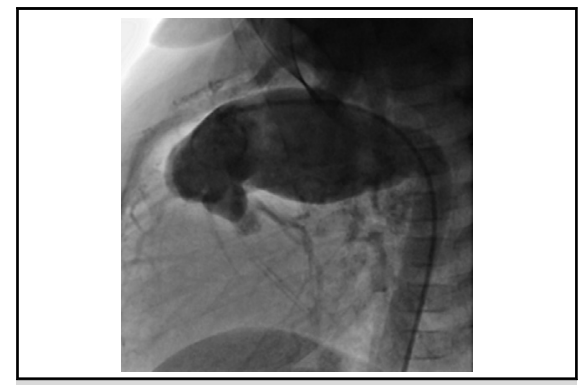

After the Norwood, the neoaorta shows abnormal geometry and ascending aortic dilation.

\section{Central Message}

After Norwood surgery, the reconstructed neoaorta demonstrates abnormal geometry, ascending aortic dilation, and reduced distensibility, with variation seen between centers

\section{Perspective}

We analyzed prestage II palliation aortic angiograms from the PHN Single Ventricle Reconstruction Trial subjects. Reconstructed neoaortas demonstrated abnormal arch geometry, ascending dilation, and reduced distensibility. These factors were not associated with reduced RV function on the 14-month echocardiogram. The longer-term impact of these abnormalities warrants further study.

See Editorial Commentary page 480 .

\footnotetext{
From the ${ }^{a}$ Duke University Medical Center, Durham, NC; ${ }^{b}$ Medical University of South Carolina, Charleston, SC; 'Children's Hospital of Wisconsin, Milwaukee, Wis; ${ }^{\text {d}}$ Children's Healthcare of Atlanta, Emory University School of Medicine, Atlanta, Ga; ${ }^{\mathrm{e}}$ Children's Hospital of Philadelphia, Philadelphia, Pa; ${ }^{\mathrm{f} C i n c i n n a t i}$ Children's Hospital Medical Center, Cincinnati, Ohio; ${ }^{\mathrm{g}}$ Johns Hopkins Children's Heart Surgery, All Children's Hospital and Florida Hospital for Children, St Petersburg, Tampa, and Orlando; ${ }^{\mathrm{h}} \mathrm{Hospital}$ for Sick Children, Toronto, Ontario, Canada; ${ }^{\mathrm{i}}$ Children's Hospital Los Angeles, Los Angeles, Calif; ${ }^{j}$ University of Utah School of Medicine, Salt Lake City, Utah; ${ }^{k}$ Nemours Children's Health System, Wilmington, Del; 'Children's Hospital Boston, Boston, Mass; 'miami Children's Hospital, Miami, Fla; ${ }^{\mathrm{n} C}$ Columbia University Medical Center, New York, NY; and ${ }^{\mathrm{o}}$ University of Michigan Medical School, Ann Arbor, Mich.

Funded by Grant Numbers HL068269, HL068270, HL068279, HL068281, HL068285, HL068292, HL068290, HL068288, HL085057, HL109737, and
}

HL085057 from the National Heart, Lung, and Blood Institute. The views expressed in this article are those of the individual authors and do not represent official views of the National Heart, Lung, and Blood Institute or National Institutes of Health

See Appendix for a complete list of the Pediatric Heart Network Investigators.

Clinical trials registration: www.ClinicalTrials.gov (NCT00115934).

Received for publication Nov 3, 2015; revisions received March 7, 2016; accepted for publication March 13, 2016; available ahead of print May 7, 2016.

Address for reprints: Kevin D. Hill, MD, MS, Duke Clinical Research Institute, 2400 Pratt St, Durham, NC 27705 (E-mail: kevin.hill@ duke.edu).

0022-5223/\$36.00

Copyright (c) 2016 by The American Association for Thoracic Surgery

http://dx.doi.org/10.1016/j.jtcvs.2016.03.091 


$$
\begin{aligned}
& \text { Abbreviations and Acronyms } \\
& \text { CI = confidence interval } \\
& \text { mBTS }=\text { modified Blalock-Taussig shunt } \\
& \text { MRI = magnetic resonance imaging } \\
& \mathrm{OR}=\text { odds ratio } \\
& \text { PHN }=\text { Pediatric Heart Network } \\
& \mathrm{RV}=\text { right ventricle } \\
& \text { RVPAS = right ventricle-pulmonary artery shunt } \\
& \text { SVR = Single Ventricle Reconstruction }
\end{aligned}
$$

\section{Scanning this QR code will take you to supplemental figure, tables, and imaging video for this article.}

Despite advances in care, children born with hypoplastic left heart syndrome and related single right ventricle (RV) lesions continue to demonstrate high mortality rates. ${ }^{1,2}$ Mortality risk is greatest in neonates and infants. However, there is continued attrition beyond infancy, and survivors have significant morbidities and reduced functional and exercise capacity. ${ }^{3-5}$

To reduce long-term morbidity and mortality, surgeons have sought to optimize efficiency of the palliated singleventricle circulation. Several studies have identified alternative surgical approaches to improve flow dynamics of the total cavopulmonary connection..$^{6-9}$ In contrast, a relatively understudied source of circulatory inefficiency is the reconstructed neoaorta where higher pressures and greater flow velocities predict greater potential for energy loss than in the total cavopulmonary connection. ${ }^{10}$ Potentially maladaptive neoaortic properties, including abnormal geometry, ascending neoaortic dilation, and reduced wall distensibility, have been described in single-center analyses and have been associated with increased power loss and ventricular dysfunction. ${ }^{10-14}$ However, in the absence of multicenter data, it remains unclear whether these maladaptive neoaortic properties are universally present after aortic arch reconstruction or they may be related to individual surgeon technique or other center-specific factors. Moreover, risk factors that contribute to abnormal arch geometry, morphology, and physiology have not been evaluated, and no multicenter evaluation has assessed whether maladaptive neoaortic properties affect outcomes.

The National Heart, Lung, and Blood Institute-sponsored Pediatric Heart Network (PHN) Single Ventricle Reconstruction (SVR) trial enrolled the largest multicenter prospective cohort of infants with hypoplastic left heart syndrome or related single RV congenital heart disease with longitudinal follow-up after the Norwood procedure. ${ }^{3,15}$ As part of the SVR trial, prestage II angiograms were evaluated at an angiographic core laboratory, providing a unique opportunity to study neoaortic arch anatomy and physiology in a large multicenter cohort. The objectives of this analysis were (1) to describe neoaortic arch morphology and physiology in this cohort in comparison with single-ventricle controls who did not require aortic reconstruction; (2) to assess the frequency of and risk factors for ascending neoaortic dilation and reduced distensibility; and (3) to determine the impact of ascending neoaortic dilation and reduced distensibility on RV function after arch reconstruction.

\section{MATERIALS AND METHODS Study Design and Sample}

The SVR trial was a prospective study comparing outcomes in patients with single RV between subjects randomized to a modified Blalock-Taussig shunt (mBTS) or a right ventricle-pulmonary artery shunt (RVPAS) at the time of the Norwood procedure. Details of the trial design and primary results have been reported. ${ }^{3,15}$ We performed a retrospective cohort study using data from the SVR trial and supplemented the analysis by making comparisons with a concurrent single-ventricle control population with no history of surgical arch intervention. For the SVR trial population, 549 subjects comprised the original analytic cohort. Of these, 389 survived and underwent cardiac catheterization before stage II palliation (superior cavopulmonary anastomosis), and 326 (84\%) had aortic arch angiographic images of adequate quality for the required measurements. The control population was identified from the angiographic database at Duke University and consisted of 50 patients with single left ventricles with no prior arch reconstruction who were undergoing prestage II catheterization during the concurrent time period as the SVR trial. Diagnoses in the control population included pulmonary atresia/intact ventricular septum $(n=19)$, tricuspid atresia $(n=11)$, double inlet left ventricle $(n=7)$, right dominant unbalanced atrioventricular canal $(n=7)$, and a subset of complex single left ventricle lesions $(n=7) ; 5$ patients $(10 \%)$ had no surgical intervention before undergoing superior cavopulmonary anastomosis, 9 patients $(18 \%)$ underwent pulmonary artery banding, and the majority $(\mathrm{n}=36,72 \%)$ received a systemic to pulmonary artery shunt. Arch measurements (descriptions follow) were all similar between control subjects receiving a systemic to pulmonary arterial shunt and those who did not; therefore, the control subjects were compared collectively with the SVR cohort. For the SVR cohort, the Institutional Review Board at each participating center approved the trial. Written informed consent was obtained from 1 or both parents. For controls, the Duke University Medical Center Institutional Review Board approved the data collection with waiver of informed consent.

\section{Study Measurements}

In the population with SVR, detailed preoperative medical history was recorded before the Norwood procedure, including demographics, subject characteristics, and anatomic diagnosis. Operative variables collected included shunt type, use of coarctectomy and patch material (yes/no), origin of shunt, bypass time, and additional cardiac operations. All postNorwood interventions were recorded, and cases of recoarctation were defined as those for which surgical or catheter-based intervention was performed by 12 months after randomization as previously described. ${ }^{16}$ Cardiac catheterizations before stage II palliation were performed at the discretion of the individual centers. Hemodynamic data were collected for all subjects who underwent catheterization and submitted to the data coordinating center. Angiographic analysis of both the SVR study cohort and the control population was performed at Duke University, which served 
as the SVR trial angiographic core laboratory. Angiographic assessment of the neoaorta was performed in the lateral projection by a single investigator who was blinded to both patient and center. Global aortic arch geometry was objectively quantified by measuring the arch width to height ratio and subjectively classified on the basis of previously described definitions as gothic, crenel, or normal (Romanesque). ${ }^{17}$ The gothic arch has a triangular form with a more acute angulation between the plane of the ascending and descending aorta and is typically characterized by an arch height that is greater than the arch width. The crenel arch has a more rectangular form with an arch width that is typically greater than the arch height. Normal arch geometry (Romanesque) is defined as a smooth semicircular form with an approximate 1:1 height to width ratio (Figure 1, $A$ ). The diameter of the ascending neoaorta was measured during systole and diastole at 2 separate locations: at the largest point and just above the sinotubular junction. The descending aorta was measured during systole and diastole at the diaphragm. Additional measurements of aortic diameter were made at the proximal transverse aorta, distal transverse aorta, isthmus, and descending aorta at the area of poststenotic dilation (Figure E1). Arch measurements were indexed to body surface area. Ascending aortic $Z$ scores were calculated using previously reported nomograms for echocardiography. ${ }^{18}$

The aortic index was defined as the ratio between the ascending aortic diameter in systole measured at the largest point and the diameter of the descending aorta in systole measured at the level of the diaphragm. The distensibility index was calculated for the ascending neoaorta based on an average of the 2 measurements described earlier (above the sinotubular junction and at the largest point) and the descending aorta at the diaphragm as previously described using the following calculation: Distensibility $\left(10^{-3} \mathrm{~mm} \mathrm{Hg}^{-1}\right)=\left(A_{\max }-A_{\min }\right) /\left[A_{\min } \times\left(P_{\max }-P_{\min }\right)\right] . \mathrm{A}_{\max }$ and $\mathrm{A}_{\text {min }}$ represent the maximal (systole) and minimal (diastole) crosssectional area of the aorta measured at the same point, and $\mathrm{P}_{\max }$ and $\mathrm{P}_{\min }$ are the systolic and diastolic ascending aortic blood pressures obtained during catheterization hemodynamic assessment, respectively. ${ }^{13}$ Aortic cross-sectional area was calculated using the following calculation: cross-sectional area $=\pi(D / 2)^{2}$, where $\mathrm{D}$ represents the measured diameter of the aorta on angiogram.

Echocardiograms were obtained after the Norwood procedure, before stage II surgery during the preoperative evaluation, and at 14 months of age. Echocardiograms were interpreted centrally at the SVR trial core echocardiography laboratory. Core laboratory procedures for image analysis (including the primary echocardiographic outcome of interest, RV fractional area change) and data management have been described. ${ }^{19}$

\section{Statistical Methods}

Standard summary statistics were used to describe study variables, including means and standard deviation or frequency counts with percentages. Wilcoxon rank-sum test or chi-square test was used for comparisons. We evaluated risk factors for 2 a priori identified binary outcomes: increased ascending neoaorta dilation (aortic index $>75$ th percentile) and reduced distensibility (distensibility index $<25$ th percentile) using univariate analysis. Multivariable logistic regression was performed to evaluate factors associated with neoaortic dilation while allowing for withincenter correlation. Clinically relevant covariates identified as significant by univariate analysis were included in the multivariable model, and odds ratios (ORs) with $95 \%$ confidence intervals (CIs) are reported. After model assumption diagnostics and collinearity testing, the following covariates remained in the model: arch geometry (categoric variable), aortic atresia (binary variable), shunt type (binary variable), native ascending aorta diameter (continuous variable), and presence of recoarctation (binary variable). We used Spearman's rho to assess the correlation between ascending aortic dilation or reduced distensibility and change in RV function between prestage II and 14-month echocardiogram. We also assessed a discrete outcome measure, defined a priori as $5 \%$ or greater decrease in RV fractional area change between the 2 echocardiograms. We conducted all analyses using Stata 13.1 (StataCorp LP, College Station, Tex).

\section{RESULTS \\ Cohort Demographics}

There were no significant differences between the SVR and control subjects with respect to age at prestage II catheterization ( $4.6 \pm 1.8$ months vs $5.0 \pm 1.7$ months; $P=.06$ ). However, the SVR subjects weighed less $(5.6 \pm 1.1 \mathrm{~kg}$ vs $6.2 \pm 1.7 \mathrm{~kg} ; P<.01)$ and were more frequently male $(62 \%$ vs $44 \% ; P<.01)$.

\section{Aortic Arch Geometry}

Arch geometry is summarized in Figure 1, A. Overall, $33 \%(\mathrm{n}=108)$ of the SVR cohort had Romanesque (normal) arch geometry compared with $78 \%(\mathrm{n}=39)$ of the single-ventricle controls $(P<.001)$. The most common geometric subtype for the SVR cohort was the elongated or crenel subtype $(\mathrm{n}=186,58 \%)$ with a width-to-height ratio of $2.0 \pm 0.6$, followed by the Romanesque subtype $(\mathrm{n}=108,33 \%$, ratio $=1.1 \pm 0.3)$. Least common was the gothic subtype $(\mathrm{n}=29,9 \%$, ratio $=0.8 \pm 0.3)$. Figure 1, $B$ demonstrates select examples of arch geometry, and the Video demonstrates still frames of all of the arch angiograms for the analytic cohort.

Arch geometry varied depending on the underlying aortic morphology. Patients born with aortic atresia or an ascending aorta $2 \mathrm{~mm}$ or less were significantly less likely to have normal arch geometry ( $28 \%$ vs $45 \%$ for aortic atresia vs stenosis $[P<.01]$ and $20 \%$ vs $36 \%$ for native ascending aorta $\leq 2 \mathrm{vs}>2 \mathrm{~mm}[P=.01])$. There was also significant variability by center with the frequency of normal arch geometry ranging from as low as $17 \%$ to as high as $57 \%(P=.003)$ (Figure 2, A). Arch geometry was not significantly associated with performance of coarctectomy at the time of the Norwood or with intervention for recoarctation.

\section{Aortic Arch Dimensions and Distensibility}

Compared with the controls, SVR subjects had increased ascending neoaortic diameters $\left(55 \pm 14 \mathrm{~mm} / \mathrm{m}^{2}\right.$ vs $\left.47 \pm 10 \mathrm{~mm} / \mathrm{m}^{2} ; P<.01\right)$ and an increased aortic index (ratio of ascending to descending aorta) $(2.3 \pm 0.5$ vs $2.0 \pm 0.3$ for SVR cohort vs controls, respectively; $P<.01$ ). However, ascending aortic $Z$ scores for both cohorts were dilated $(Z$ score $3.8 \pm 2.2$ vs $2.6 \pm 2.0$ for SVR subjects vs controls, respectively, $P<.01$ ). Again, there was substantial variability across centers (Figure 2, B).

SVR subjects had similar transverse arch diameters as the controls $\left(32 \pm 11 \mathrm{~mm} / \mathrm{m}^{2}\right.$ vs $\left.28 \pm 6 \mathrm{~mm} / \mathrm{m}^{2} ; P=.14\right)$ but demonstrated narrowing at the aortic isthmus $\left(19 \pm 6 \mathrm{~mm} / \mathrm{m}^{2}\right.$ vs $22 \pm 6 \mathrm{~mm} / \mathrm{m}^{2}$ for subjects vs controls, respectively; $P<.01$ ). There were no differences between the SVR cohort and controls in the indexed diameter of the descending aorta or the aorta at the diaphragm.

Aortic distensibility also was abnormal in the SVR cohort. Relative to controls, reduced distensibility was seen for both 


\section{- Neo-aorta $\square$ Control}

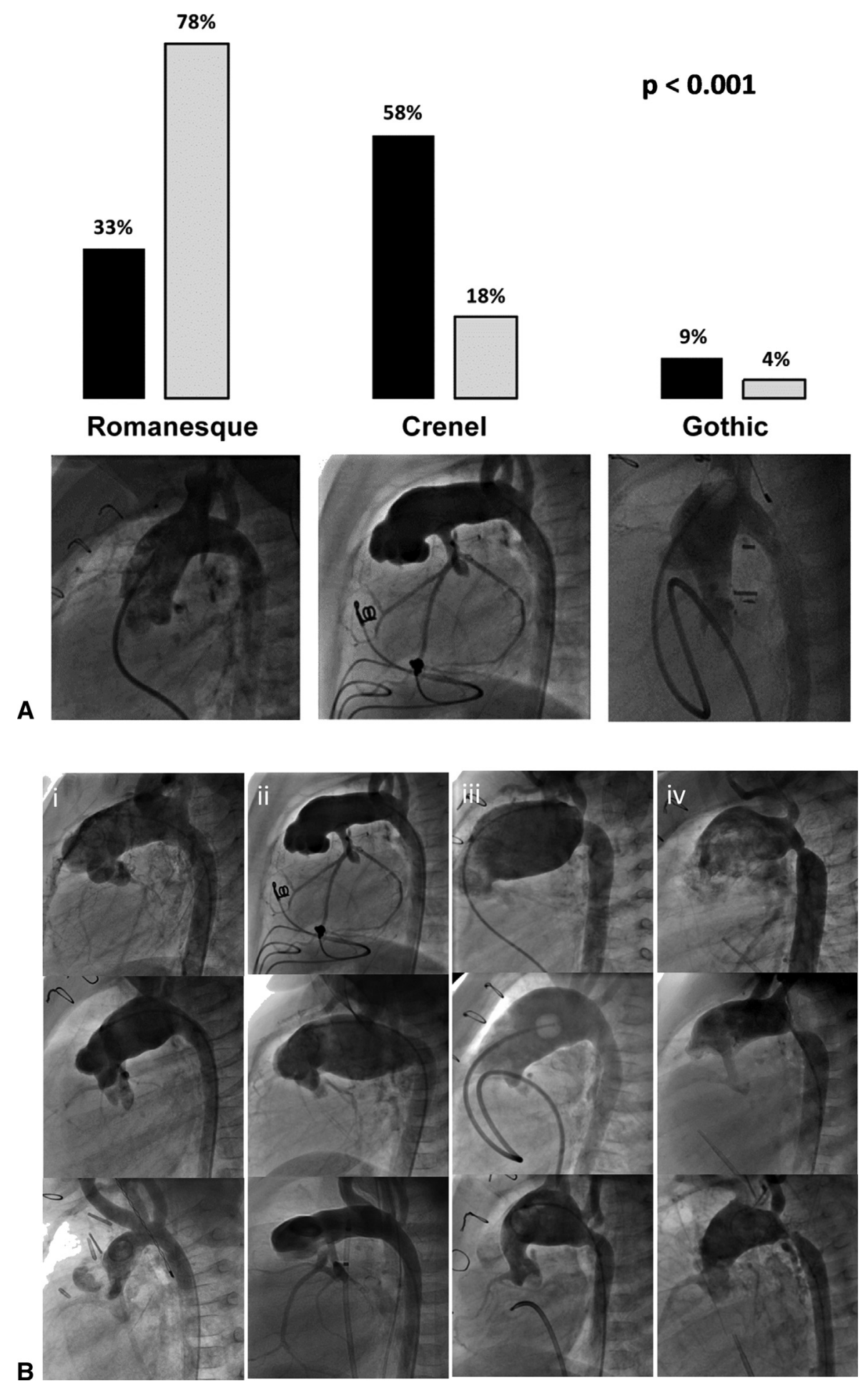

FIGURE 1. A, Arch geometry in the SVR trial cohort (neoaorta) and single ventricle controls. The $P$ value shown $(<.001)$ is for individual comparisons. The Romanesque arch has a smooth semicircular form with an approximate 1:1 height to width ratio, the crenel arch has a rectangular form with width greater than height, and the gothic arch has an angular appearance with height greater than length. B, Representative examples of neoaortic morphology and geometry. $i$, Romanesque (normal) arch geometry; $i i$, crenel arch geometry; iii, ascending neoaortic dilation; $i v$, recoarctation. 

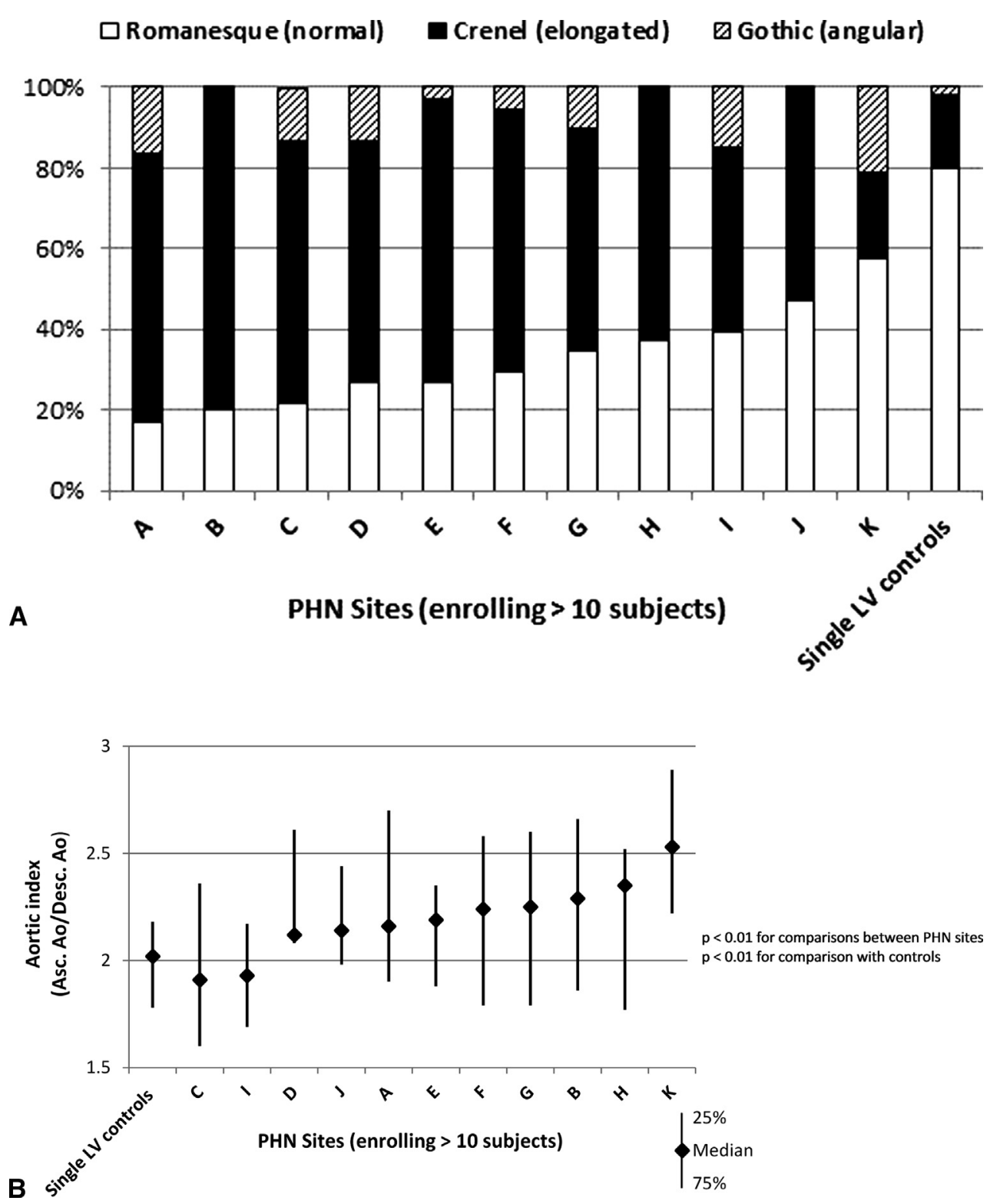

FIGURE 2. A, Variability was seen in neoaortic arch geometric classification between PHN centers. B, Reconstructed neoaortas had a greater aortic index when compared with the single-ventricle control population. Significant center variability was seen again. PHN, Pediatric Heart Network; $L V$, left ventricle; Asc, ascending; Ao, aorta; Desc, descending.

the ascending (distensibility index $=2.2 \pm 2.7 \mathrm{~mm} \mathrm{Hg}$ vs $8.0 \pm 3.8 \mathrm{~mm} \mathrm{Hg} \times 10^{-3}$, respectively; $\left.P<.01\right)$ and descending aorta $(7.4 \pm 5.3$ vs $12.6 \pm 6.4 ; P<.01)$.

\section{Factors Associated With Aortic Dilation and Reduced Distensibility}

Table 1 summarizes the factors associated by univariate analysis with an ascending aortic index 2.5 or greater (upper 25th percentile) in the SVR cohort. By multivariable analysis (Table 2), factors predicting increased ascending aortic index included receipt of an RVPAS (OR, 3.4 [95\% CI, 1.8$6.8]$ vs mBTS, $P<.01)$ and gothic arch geometry (OR, 3.2
[95\% CI, 1.1-9.2] vs crenel geometry, $P<.01$ ). Conversely, patients with aortic atresia $(\mathrm{OR}, 0.7 ; 95 \% \mathrm{CI}, 0.5-0.8$; $P<.01)$ or who received intervention for recoarctation (OR, 0.3; 95\% CI, 0.1-0.9; $P=.03$ ) tended to have a smaller ascending aortic index. The association between recoarctation and aortic index was unchanged when excluding patients with intervention for recoarctation occurring before the prestage II catheterization $(n=2)$ and when excluding those who did not have recoarctation intervention until stage II surgery or later $(\mathrm{n}=18)$. There were no identifiable risk factors for decreased neoaortic distensibility (Table E1). 
TABLE 1. Univariate analysis: Factors associated with ascending aortic dilation (aortic index $\geq 2.5$ )

\begin{tabular}{|c|c|c|c|c|}
\hline & $\mathbf{n}$ & $\begin{array}{l}\mathrm{AI} \geq 2.5 \\
(\mathrm{n}=82)\end{array}$ & $\begin{array}{c}\mathrm{AI}<2.5 \\
(\mathrm{n}=\mathbf{2 2 9})\end{array}$ & $P$ value \\
\hline \multicolumn{5}{|l|}{ Demographic features } \\
\hline Gestational age, wk & 311 & $38.1 \pm 1.7$ & $38.4 \pm 1.3$ & .30 \\
\hline Birth weight, $g$ & 311 & $3167 \pm 548$ & $3176 \pm 527$ & .94 \\
\hline Arch geometry & 311 & & & $<.01$ \\
\hline Romanesque (normal) & 106 & $35(33 \%)$ & $71(67 \%)$ & \\
\hline Crenel (elongated) & 176 & $35(20 \%)$ & $141(80 \%)$ & \\
\hline Gothic (angular) & 29 & $12(41 \%)$ & $17(59 \%)$ & \\
\hline \multicolumn{5}{|l|}{ Morphologic features } \\
\hline HLHS subtype & 276 & & & $<.01$ \\
\hline Aortic atresia & & $41(21 \%)$ & $151(79 \%)$ & \\
\hline Aortic stenosis & & $31(37 \%)$ & $53(63 \%)$ & \\
\hline Native AAo size & 307 & & & .19 \\
\hline$\leq 2 \mathrm{~mm}$ & & $9(19 \%)$ & $39(81 \%)$ & \\
\hline$>2 \mathrm{~mm}$ & & $72(28 \%)$ & $187(72 \%)$ & \\
\hline Recoarctation & 311 & $12(16 \%)$ & $62(84 \%)$ & .03 \\
\hline Aortic isthmus, $\mathrm{mm} / \mathrm{m}^{2}$ & 311 & $18.3 \pm 5.3$ & $16.7 \pm 10.1$ & .28 \\
\hline \multicolumn{5}{|l|}{ Surgical variables } \\
\hline Bypass time, min & 311 & $139 \pm 41$ & $140 \pm 54$ & .63 \\
\hline Coarctectomy & 311 & $23(23 \%)$ & $76(77 \%)$ & .39 \\
\hline $\begin{array}{l}\text { Shunt type } \\
\quad \text { (intention to treat) }\end{array}$ & 311 & & & .02 \\
\hline mBTS & 141 & $28(20 \%)$ & $113(80 \%)$ & \\
\hline RVPAS & 170 & $54(32 \%)$ & $116(68 \%)$ & \\
\hline $\begin{array}{l}\text { Shunt type (actual } \\
\text { shunt received) }\end{array}$ & 311 & & & $<.01$ \\
\hline mBTS & 133 & $22(17 \%)$ & $111(83 \%)$ & \\
\hline RVPAS & 178 & $60(34 \%)$ & $118(66 \%)$ & \\
\hline \multicolumn{5}{|l|}{ Aortic physiology } \\
\hline AAo distensibility index & 226 & $2.4 \pm 1.6$ & $2.3 \pm 3.0$ & .20 \\
\hline DAo distensibility index & 226 & $7.64 \pm 5.26$ & $8.81 \pm 5.29$ & .07 \\
\hline
\end{tabular}

Data represent mean \pm standard deviation or $\mathrm{n}(\%)$ as appropriate. Percentages represent row percentages. AI, Aortic index; HLHS, hypoplastic left heart syndrome; $A A o$, ascending aorta; $m B T S$, modified Blalock-Taussig shunt; RVPAS, right ventriclepulmonary artery shunt; $D A o$, descending aorta.

\section{Outcomes}

When assessed as a continuous outcome measure, there was no correlation between change in RV fractional area change and ascending aortic dimension or ascending aortic distensibility index. Overall, $34 \%(n=77)$ of the SVR trial patients met the prespecified "cut point" for decreased RV function $(\geq 5 \%$ decrease in fractional area change between prestage II echocardiogram and 14-month follow-up echocardiogram). When using this measure of decline in RV function, there was again no association with ascending aortic dilation or reduced distensibility (Table E2).

\section{DISCUSSION}

In this analysis of aortic angiograms from the multicenter PHN SVR trial cohort, we demonstrate a high prevalence of potentially maladaptive aortic features, including abnormal arch geometry, ascending aortic dilation, and markedly reduced distensibility. The relative prevalence of these
TABLE 2. Multivariate analysis: Factors associated with ascending aortic dilation (aortic index $\geq 2.5$ )

\begin{tabular}{lccr}
\hline & OR & $\mathbf{9 5} \%$ CI & $\boldsymbol{P}$ value \\
\hline Arch geometries & & & \\
$\quad$ Crenel & Referent & & \\
$\quad$ Romanesque & 1.7 & $0.6-4.5$ & .32 \\
$\quad$ Gothic & 3.2 & $1.1-9.2$ & .03 \\
Aortic atresia (vs stenosis) & 0.7 & $0.5-0.8$ & $<.01$ \\
RVPAS (vs mBTS) & 3.4 & $1.8-6.8$ & $<.01$ \\
Native AAo diameter (per mm & 1.1 & $0.9-1.3$ & .24 \\
$\quad$ increase) & & & \\
Recoarctation & 0.3 & $0.1-0.9$ & .04 \\
\hline OR, Odds ratio; $C I$, confidence interval; $R V P A S$, right ventricle-pulmonary artery \\
shunt; $m B T S$, modified Blalock-Taussig shunt; $A A o$, ascending aorta.
\end{tabular}

anatomic and physiologic features varied substantially between PHN centers, suggesting that physiology and postsurgical anatomy may be modifiable. However, we found no association between ascending aortic dilation or reduced distensibility and RV fractional area change measured by echocardiogram at 14-month follow-up.

An emerging body of literature indicates that abnormal geometry, morphology, and physiology in the reconstructed aorta contribute to increased wall shear stress, energy loss, and increased afterload. ${ }^{12,20,21}$ By using computational fluid dynamic modeling, Itatani and colleagues ${ }^{10}$ demonstrated up to $15 \%$ energy loss in the reconstructed neoaorta after the Norwood surgery that was due to abnormal geometry and wall stress. They found that greater curvature of the arch resulted in the lowest amount of energy loss and that this was related to surgical technique. Similar findings have been demonstrated in patients with abnormal arch geometry after surgically repaired coarctation of the aorta, and of note, in these patients abnormal arch geometry is associated with increased left ventricular mass and increased prevalence of hypertension. ${ }^{22-24}$ These analyses after coarctation repair suggest that gothic (increased height to length ratio) arch geometry is the least favorable. ${ }^{22-24}$ Our findings are consistent with this interpretation because gothic arches demonstrated the greatest propensity for ascending aortic dilation and reduced distensibility, although the latter finding did not reach statistical significance. Relative to single left ventricle controls, few patients with single RV demonstrated the optimal curved geometry of the Romanesque aortic arch.

The typical arch morphology in our analysis also is abnormal, characterized by a markedly dilated ascending aorta with tapering across the transverse aorta to a narrowed aortic isthmus (Video 1). Voges and colleagues ${ }^{12}$ had similar findings in their single-center analysis with an ascending aortic index of 1.9-2.1 in their single-ventricle patients (vs normal controls in whom the aortic index was 1.2-1.4). Dilation of the neoaortic root and ascending neoaorta has been described in other single-center analyses. ${ }^{12,25}$ Cohen and colleagues ${ }^{11}$ found that the neoaortic valve annulus, aortic 
root, and sinotubular junction dilate progressively over time and that the extent of dilation is associated with an increased prevalence of neoaortic insufficiency. A recent analysis of the PHN cohort demonstrated a low $4 \%$ prevalence of significant (moderate or more) neoaortic insufficiency. ${ }^{26} \mathrm{How}-$ ever, follow-up in this analysis was short with no data after Fontan surgery. It is possible that neoaortic insufficiency associated with root dilation is a longer-term problem. Aortic root dilation also is seen in patient populations in whom the pulmonary valve functions as the neoaortic valve, such as after the Ross procedure or arterial switch operations. ${ }^{27-29}$ The Ross procedure increasingly is being performed with reinforcement of the aortic root to prevent dilation and associated aortic insufficiency. ${ }^{30,31}$ The Norwood operation differs from the Ross and arterial switch operations because the entire ascending aorta is reconstructed, and, as we demonstrate, dilation extends beyond the aortic root into the ascending and transverse arch.

Patients with single RVs also demonstrated markedly abnormal physiology with approximately 4 -fold reduced ascending neoaortic distensibility when compared with single left ventricle controls. Studies using magnetic resonance imaging (MRI) data have demonstrated that reduced distensibility of the reconstructed neoaorta contributes to suboptimal ventricular-vascular coupling, increased afterload, and energy loss. ${ }^{12,14}$ Voges and colleagues, ${ }^{12}$ in an analysis of 40 patients with palliated single-ventricle lesions, found that reduced distensibility and late gadolinium enhancement (a marker of fibrosis and scar tissue) of the ascending neoaorta correlate closely with decreased RV ejection fraction measured by cardiac MRI. ${ }^{12}$ Although we found no correlation with RV fractional area change, there are limitations associated with echocardiographic quantification of RV function, and our analysis included a relatively short time frame of follow-up. Without definitive data, our concerns regarding the long-term implications of abnormal arch geometry, morphology, and physiology remain relatively speculative, founded on simulation models and single-center analyses, or extrapolated from other patient populations. More in-depth analysis may be feasible in the future as plans are under way to obtain MRI data at long-term follow-up in the SVR trial cohort.

Although hard evidence of a deleterious impact is lacking, it seems prudent to evaluate potentially modifiable factors that may influence neoaortic form and function. Native aortic anatomy obviously is not a modifiable factor, and the presence of aortic atresia was associated with abnormal geometry and a smaller ascending neoaortic diameter. However, the substantial center variability suggests that surgical technique plays a role. In support of this, Mahle and colleagues $^{25}$ demonstrated that long-term neoaortic dimensions are most closely related to the immediate postsurgical dimension. Approaches to the Norwood arch reconstruction have evolved over time using variations of patch material (homografts, autografts, and extracellular matrix biomaterials) and differing techniques (eg, using coarctectomy with or without interdigitation). We did not demonstrate an association between aortic dilation and the use of coarctectomy; however, further analysis in this cohort was limited because we did not have detailed operative data (including data on use of interdigitation or the specifics of patch material).

Physiologic factors also may influence ascending aortic dimensions. We hypothesized that we would see greater ascending aortic dilation in the mBTS group due to the wider pulse pressure and greater volume load traversing the ascending neoaorta. However, we found the opposite; patients with an mBTS had a significantly smaller ascending aortic index than those with an RVPAS. It is possible that the ascending aorta in the RVPAS group dilates more in the anteroposterior plane because of space constraints from the shunt. Because of difficulties visualizing the ascending aorta in the anteroposterior projection, our measurements were all made in the lateral projection. Alternatively, this finding may be spurious or related to imbalance between the 2 shunt groups because of increased prestage II mortality in the mBTS group. ${ }^{3}$ In addition to shunt type, we also demonstrated that patients undergoing intervention for recoarctation were less likely to demonstrate ascending neoaortic dilation. This likely reflects a higher risk of recoarctation in patients with smaller native aortae. However, this finding does suggest that distal obstruction is not the cause for ascending aortic dilation.

\section{Study Limitations}

Limitations of the current study include all of the limitations associated with a retrospective study, including the absence of specific data on surgical technique, native aortic arch anatomy, and other anatomic considerations that may affect postoperative anatomy. In addition, cardiac catheterization and aortic angiography were not required for SVR trial participants. Although generally accepted as standard of care, there were some patients who did not undergo prestage II cardiac catheterization or did not have interpretable aortic angiograms. Another limitation is that our distensibility index and ascending aortic $Z$ scores were calculated using data from single-plane (lateral) angiograms, reducing a 3-dimensional structure to a 2-dimensional construct. In addition, these indices were developed using echocardiographic or 3-dimensional MRI data in patients with normal aortae. They have not been previously used to describe angiographic data after aortic arch reconstruction. It is possible that our absolute numbers do not compare accurately with normative echocardiographic or MRI data. However, angiographic comparisons between SVR subjects and controls should be reliable. Finally, there are several study limitations that may have affected our ability to detect 


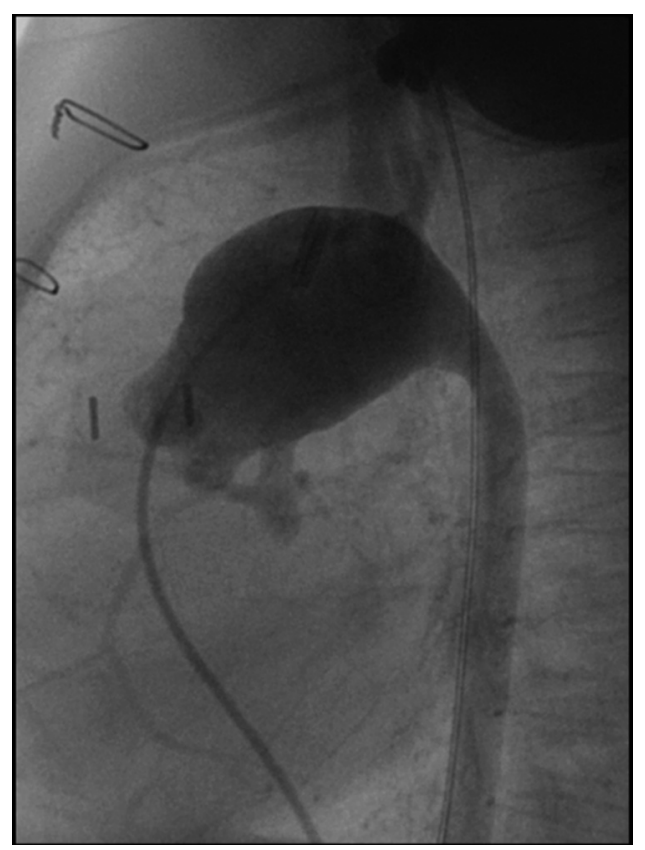

VIDEO 1. This video provides snapshot views of angiograms from all of the SVR trial aortae demonstrating the wide variability in aortic morphology. Video available at: http://www.jtcvsonline.org/article/ S0022-5223(16)30114-3/addons.

a relationship between aortic properties and RV function, including the well-recognized limitations associated with echocardiographic quantification of RV function, the relatively short time frame of follow-up, and the fact that a significant percentage of our cohort had abnormal baseline RV function, suggesting that RV dysfunction is multifactorial, making it harder to isolate any single factor that might contribute to RV dysfunction. For all of these reasons, we are hesitant to reject the hypothesis that aortic morphology and physiology have a deleterious impact on long-term RV function.

\section{CONCLUSIONS}

We analyzed neoaortic angiograms from the multicenter PHN SVR trial cohort. Neoaortic arch geometry, morphology, and distensibility all are abnormal in these patients with single RV lesions. The implications of these variations in form and function are not yet known, and we did not find a specific association between any of these features and RV function measured by echocardiography at intermediate-term follow-up. Nonetheless, it is clear that there is substantial variability across centers, and future studies are needed to determine whether these neoaortic abnormalities might influence patient outcomes.

\section{Conflict of Interest Statement}

C.P.H., J.S.L., and K.D.H. receive support from the National Center for Advancing Translational Sciences of the National Institutes of Health (UL1TR001117). All other authors have nothing to disclose with regard to commercial support.

\section{References}

1. Centers for Disease Control and Prevention (CDC). Hospital stays, hospital charges, and in-hospital deaths among infants with selected birth defects-United States, 2003. MMWR Morb Mortal Wkly Rep. 2007;56:25-9.

2. Fixler DE, Nembhard WN, Salemi JL, Ethen MK, Canfield MA. Mortality in first 5 years in infants with functional single ventricle born in Texas, 1996 to 2003. Circulation. 2010;121:644-50.

3. Ohye RG, Sleeper LA, Mahony L, Newburger JW, Pearson GD, Lu M, et al; Pediatric Heart Network Investigators. Comparison of shunt types in the Norwood procedure for single-ventricle lesions. N Engl J Med. 2010;362:1980-92.

4. Newburger JW, Sleeper LA, Frommelt PC, Pearson GD, Mahle WT, Chen S, et al. Transplantation-free survival and interventions at 3 years in the single ventricle reconstruction trial. Circulation. 2014;129:2013-20.

5. Anderson PA, Sleeper LA, Mahony L, Colan SD, Atz AM, Breitbart RE, et al; Pediatric Heart Network Investigators. Contemporary outcomes after the Fontan procedure: a Pediatric Heart Network multicenter study. J Am Coll Cardiol. 2008;52:85-98.

6. Marsden AL, Bernstein AJ, Reddy VM, Shadden SC, Spilker RL, Chan FP, et al. Evaluation of a novel Y-shaped extracardiac Fontan baffle using computational fluid dynamics. J Thorac Cardiovasc Surg. 2009;137:394-403.e2.

7. de Leval MR, Dubini G, Migliavacca F, Jalali H, Camporini G, Redington A, et al. Use of computational fluid dynamics in the design of surgical procedures: application to the study of competitive flows in cavo-pulmonary connections. J Thorac Cardiovasc Surg. 1996;111:502-13.

8. Bove EL, de Leval MR, Migliavacca F, Guadagni G, Dubini G. Computational fluid dynamics in the evaluation of hemodynamic performance of cavopulmonary connections after the Norwood procedure for hypoplastic left heart syndrome. J Thorac Cardiovasc Surg. 2003;126:1040-7.

9. Whitehead KK, Pekkan K, Kitajima HD, Paridon SM, Yoganathan AP, Fogel MA. Nonlinear power loss during exercise in single-ventricle patients after the Fontan: insights from computational fluid dynamics. Circulation. 2007;116: I165-71.

10. Itatani K, Miyaji K, Qian Y, Liu JL, Miyakoshi T, Murakami A, et al. Influence of surgical arch reconstruction methods on single ventricle workload in the Norwood procedure. J Thorac Cardiovasc Surg. 2012;144:130-8.

11. Cohen MS, Marino BS, McElhinney DB, Robbers-Visser D, van der Woerd W, Gaynor JW, et al. Neo-aortic root dilation and valve regurgitation up to 21 years after staged reconstruction for hypoplastic left heart syndrome. J Am Coll Cardiol. 2003;42:533-40.

12. Voges I, Jerosch-Herold M, Hedderich J, Westphal C, Hart C, Helle M, et al. Maladaptive aortic properties in children after palliation of hypoplastic left heart syndrome assessed by cardiovascular magnetic resonance imaging. Circulation. 2010;122:1068-76.

13. Cardis BM, Fyfe DA, Mahle WT. Elastic properties of the reconstructed aorta in hypoplastic left heart syndrome. Ann Thorac Surg. 2006;81:988-91.

14. Biglino G, Schievano S, Steeden JA, Ntsinjana H, Baker C, Khambadkone S, et al; Modeling of Congenital Hearts Alliance Collaborative Group. Reduced ascending aorta distensibility relates to adverse ventricular mechanics in patients with hypoplastic left heart syndrome: noninvasive study using wave intensity analysis. J Thorac Cardiovasc Surg. 2012;144:1307-14.

15. Ohye RG, Gaynor JW, Ghanayem NS, Goldberg CS, Laussen PC, Frommelt PC, et al. Design and rationale of a randomized trial comparing the Blalock-Taussig and right ventricle-pulmonary artery shunts in the Norwood procedure. J Thorac Cardiovasc Surg. 2008;136:968-75.

16. Hill KD, Rhodes JF, Aiyagari R, Baker GH, Bergersen L, Chai PJ, et al. Intervention for recoarctation in the single ventricle reconstruction trial: incidence, risk, and outcomes. Circulation. 2013;128:954-61.

17. Ou P, Bonnet D, Auriacombe L, Pedroni E, Balleux F, Sidi D, et al. Late systemic hypertension and aortic arch geometry after successful repair of coarctation of the aorta. Eur Heart J. 2004;25:1853-9.

18. Gautier M, Detaint D, Fermanian C, Aegerter P, Delorme G, Arnoult F, et al. Nomograms for aortic root diameters in children using two-dimensional echocardiography. Am J Cardiol. 2010;105:888-94.

19. Frommelt PC, Guey LT, Minich LL, Bhat M, Bradley TJ, Colan SD, et al; Pediatric Heart Network Investigators. Does initial shunt type for the Norwood procedure affect echocardiographic measures of cardiac size and function during 
infancy?: the Single Ventricle Reconstruction trial. Circulation. 2012;125: 2630-8.

20. Fogel MA, Weinberg PM, Hoydu AK, Hubbard AM, Rychik J, Jacobs ML, et al. Effect of surgical reconstruction on flow profiles in the aorta using magnetic resonance blood tagging. Ann Thorac Surg. 1997;63:1691-700.

21. Milnor WR. Arterial impedance as ventricular afterload. Circ Res. 1975;36:565-70.

22. Ou P, Celermajer DS, Raisky O, Jolivet O, Buyens F, Herment A, et al. Angular (Gothic) aortic arch leads to enhanced systolic wave reflection, central aortic stiffness, and increased left ventricular mass late after aortic coarctation repair: evaluation with magnetic resonance flow mapping. J Thorac Cardiovasc Surg. 2008; $135: 62-8$.

23. Szopos M, Poussineau N, Maday Y, Canniffe C, Celermajer DS, Bonnet D, et al. Computational modeling of blood flow in the aorta-insights into eccentric dilatation of the ascending aorta after surgery for coarctation. J Thorac Cardiovasc Surg. 2014;148:1572-82.

24. Ou P, Celermajer DS, Mousseaux E, Giron A, Aggoun Y, Szezepanski I, et al. Vascular remodeling after "successful" repair of coarctation: impact of aortic arch geometry. J Am Coll Cardiol. 2007;49:883-90.

25. Mahle WT, Rychik J, Weinberg PM, Cohen MS. Growth characteristics of the aortic arch after the Norwood operation. J Am Coll Cardiol. 1998;32:1951-4.

26. Frommelt PC, Gerstenberger E, Cnota JF, Cohen MS, Gorentz J, Hill KD, et al; Pediatric Heart Network Investigators. Impact of initial shunt type on cardiac size and function in children with single right ventricle anomalies before the Fontan procedure: the single ventricle reconstruction extension trial. J Am Coll Cardiol. 2014;64:2026-35.

27. Pasquali SK, Cohen MS, Shera D, Wernovsky G, Spray TL, Marino BS. The relationship between neo-aortic root dilation, insufficiency, and reintervention following the Ross procedure in infants, children, and young adults. $J$ Am Coll Cardiol. 2007;49:1806-12.

28. van der Bom T, van der Palen RL, Bouma BJ, van Veldhuisen SL, Vliegen HW, Konings TC, et al. Persistent neo-aortic growth during adulthood in patients after an arterial switch operation. Heart. 2014;100:1360-5.

29. Bottio T, Thiene G, Tarzia V, Rizzoli G, Gerosa G. Arterial switch operation, aortic root dilation, and long-term aortic valve competence. Ann Thorac Surg. 2008;86:2025-6.

30. Al Rashidi F, Bhat M, Hoglund P, Meurling C, Roijer A, Koul B. The modified Ross operation using a Dacron prosthetic vascular jacket does prevent pulmonary autograft dilatation at 4.5-year follow-up. Eur J Cardiothorac Surg. 2010;37: 928-33.

31. Koul B, Al-Rashidi F, Bhat M, Meurling C. A modified Ross operation to preven pulmonary autograft dilatation. Eur J Cardiothorac Surg. 2007;31:127-8.

Key Words: Norwood, aorta, coarctation 


\section{APPENDIX}

\section{Acknowledgments}

National Heart, Lung, and Blood Institute: Gail Pearson, Victoria Pemberton, Rae-Ellen Kavey,* Mario Stylianou, Marsha Mathis*.

Network Chair: University of Texas Southwestern Medical Center, Lynn Mahony.

Data Coordinating Center: New England Research Institutes, Lynn Sleeper (Principal Investigator [PI]), Sharon Tennstedt (PI), Steven Colan, Lisa Virzi,* Patty Connell,* Victoria Muratov, Lisa Wruck,* Minmin Lu, Dianne Gallagher, Anne Devine,* Julie Schonbeck, Thomas Travison,* David F. Teitel.

Core Clinical Site Investigators: Children's Hospital Boston, Jane W. Newburger (PI), Peter Laussen, Pedro del Nido, Roger Breitbart, Jami Levine, Ellen McGrath, Carolyn Dunbar-Masterson, John E. Mayer, Jr, Frank Pigula, Emile A. Bacha, Francis Fynn-Thompson; Children's Hospital of New York, Wyman Lai (PI), Beth Printz,* Daphne Hsu,* William Hellenbrand,* Ismee Williams,* Ashwin Prakash,* Seema Mital,* Ralph Mosca,* Darlene Servedio,* Rozelle Corda, Rosalind Korsin, Mary Nash*; Children's Hospital of Philadelphia, Victoria L. Vetter (PI), Sarah Tabbutt,* J. William Gaynor (Study CoChair), Chitra Ravishankar, Thomas Spray, Meryl Cohen, Marisa Nolan, Stephanie Piacentino, Sandra DiLullo,* Nicole Mirarchi; Cincinnati Children's Medical Center, D. Woodrow Benson,* Catherine Dent Krawczeski, Lois Bogenschutz, Teresa Barnard, Michelle Hamstra, Rachel Griffiths, Kathryn Hogan, Steven Schwartz, ${ }^{*}$ David Nelson, Pirooz Eghtesady*; North Carolina Consortium: Duke University, East Carolina University, Wake Forest University, Page A. W. Anderson (PI) (deceased), Jennifer Li (PI), Wesley Covitz, Kari Crawford,* Michael Hines,* James Jaggers,* Theodore Koutlas, Charlie Sang, Jr, Lori Jo Sutton, Mingfen Xu; Medical University of South Carolina, J. Philip Saul,* Andrew Atz (PI), Girish Shirali,* Scott Bradley, Eric Graham, Teresa Atz, Patricia Infinger; Primary
Children's Medical Center and the University of Utah, Salt Lake City, Utah, L. LuAnn Minich (PI), John A. Hawkins (deceased), Michael Puchalski, Richard V. Williams, Peter C. Kouretas, Linda M. Lambert, Marian E. Shearrow, Jun A. Porter*; Hospital for Sick Children, Toronto, Brian McCrindle (PI), Joel Kirsh, Chris Caldarone, Elizabeth Radojewski, Svetlana Khaikin, Susan McIntyre, Nancy Slater; University of Michigan, Caren S. Goldberg (PI), Richard G. Ohye (Study Chair), Cheryl Nowak*; Children's Hospital of Wisconsin and Medical College of Wisconsin, Nancy S. Ghanayem (PI), James S. Tweddell,* Kathleen A. Mussatto, Michele A. Frommelt, Peter C. Frommelt, Lisa YoungBorkowski.

Auxiliary Sites: Children's Hospital Los Angeles, Alan Lewis (PI), Vaughn Starnes, Nancy Pike; The Congenital Heart Institute of Florida, Jeffrey P. Jacobs (PI), James A. Quintessenza, Paul J. Chai,* David S. Cooper,* J. Blaine John, James C. Huhta, Tina Merola, Tracey Griffith; Emory University, William Mahle (PI), Kirk Kanter, Joel Bond,* Jeryl Huckaby; Nemours Cardiac Center, Christian Pizarro (PI), Carol Prospero; Julie Simons, Gina Baffa, Wolfgang A. Radtke; University of Texas Southwestern Medical Center, Ilana Zeltzer (PI), Tia Tortoriello,* Deborah McElroy, Deborah Town.

Angiography Core Laboratory: Duke University, John Rhodes,* J. Curt Fudge*.

Echocardiography Core Laboratories: Children's Hospital of Wisconsin, Peter Frommelt; Children's Hospital Boston, Gerald Marx.

Genetics Core Laboratory: Children's Hospital of Philadelphia, Catherine Stolle.

Protocol Review Committee: Michael Artman (Chair); Erle Austin; Timothy Feltes, Julie Johnson, Thomas Klitzner, Jeffrey Krischer, G. Paul Matherne.

Data and Safety Monitoring Board: John Kugler (Chair); Rae-Ellen Kavey, Executive Secretary; David J. Driscoll, Mark Galantowicz, Sally A. Hunsberger, Thomas J. Knight, Holly Taylor, Catherine L. Webb.

* No longer at the institution listed. 


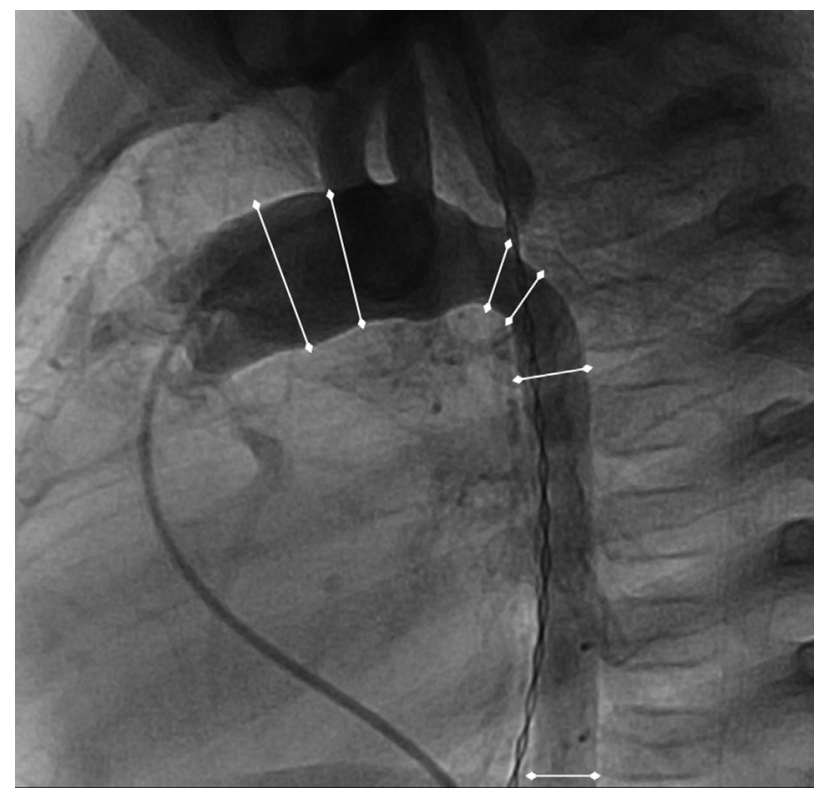

FIGURE E1. Arch diameter measurements were made in the lateral angiographic projection in the following locations: ascending aorta at the largest point (systole and diastole), proximal transverse arch, distal transverse arch, isthmus at the narrowest point, descending aorta at the largest point of poststenotic dilation, and descending aorta at the diaphragm (systole and diastole). 
TABLE E1. Factors associated with ascending aortic distensibility

\begin{tabular}{|c|c|c|c|c|}
\hline & $\mathbf{n}$ & 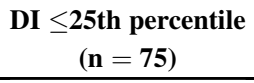 & $\begin{array}{c}\text { DI }>25 \text { th percentile } \\
(\mathrm{n}=\mathbf{2 2 5})\end{array}$ & $P$ value \\
\hline \multicolumn{5}{|l|}{ Demographic features } \\
\hline Gestational age, wk & 300 & $38.7 \pm 1.3$ & $38.3 \pm 1.5$ & .07 \\
\hline Birth weight, $g$ & 300 & $3165 \pm 580$ & $3173 \pm 515$ & .98 \\
\hline Arch geometry & & & & .33 \\
\hline Romanesque (normal) & 96 & $19(20 \%)$ & $77(80 \%)$ & \\
\hline Crenel (elongated) & 173 & $48(28 \%)$ & $125(72 \%)$ & \\
\hline Gothic (angular) & 28 & $8(29 \%)$ & $20(71 \%)$ & \\
\hline \multicolumn{5}{|l|}{ Morphologic features } \\
\hline HLHS subtype & 267 & & & .63 \\
\hline Aortic atresia & & $48(26 \%)$ & $137(74 \%)$ & \\
\hline Aortic stenosis & & $19(23 \%)$ & $63(77 \%)$ & \\
\hline Native AAo diameter & 296 & & & .90 \\
\hline$\leq 2 \mathrm{~mm}$ & & $12(26 \%)$ & $34(74 \%)$ & \\
\hline$>2 \mathrm{~mm}$ & & $63(25 \%)$ & $187(75 \%)$ & \\
\hline Recoarctation & 300 & $14(22 \%)$ & $50(78 \%)$ & .51 \\
\hline \multicolumn{5}{|l|}{ Surgical variables } \\
\hline Bypass time, min & 300 & $140 \pm 52$ & $138 \pm 50$ & .96 \\
\hline Coarctectomy & 300 & $26(27 \%)$ & $69(73 \%)$ & .52 \\
\hline Shunt type (intention to treat) & 300 & 75 & 225 & \\
\hline mBTS & & $34(25 \%)$ & $104(75 \%)$ & .89 \\
\hline RVPAS & & $41(25 \%)$ & $121(75 \%)$ & \\
\hline Shunt type (actual shunt received) & 300 & 75 & 225 & \\
\hline mBTS & & $36(27 \%)$ & $96(73 \%)$ & .42 \\
\hline RVPAS & & $39(23 \%)$ & $129(77 \%)$ & \\
\hline
\end{tabular}

Data represent mean \pm standard deviation or $\mathrm{n}(\%)$ as appropriate. Percentages represent row percentages. $D I$, Distensibility index; $H L H S$, hypoplastic left heart syndrome; $A A o$, ascending aorta; $m B T S$, modified Blalock-Taussig shunt; $R V P A S$, right ventricle-pulmonary artery shunt.

TABLE E2. Neoaortic dilation and decreased distensibility were not associated with decreased right ventricular function at 14-month follow-up

\begin{tabular}{|c|c|c|c|c|c|c|}
\hline & $\mathrm{AI} \geq \mathbf{2 . 5}(\mathrm{n}=\mathbf{8 2})$ & $\mathrm{AI}<2.5(\mathrm{n}=229)$ & $\boldsymbol{P}$ & $\begin{array}{c}\text { AAo DI }<0.7 \\
(\mathbf{n}=\mathbf{7 5})\end{array}$ & $\begin{array}{c}\text { AAo DI } \geq 0.7 \\
(\mathbf{n}=\mathbf{2 2 5})\end{array}$ & $P$ \\
\hline Pre-Glenn echocardiogram RVFAC & $34 \% \pm 7 \%$ & $33 \% \pm 8 \%$ & .14 & $33 \% \pm 8 \%$ & $35 \% \pm 7 \%$ & .10 \\
\hline 14-mo echocardiogram RVFAC & $34 \% \pm 8 \%$ & $32 \% \pm 7 \%$ & .21 & $33 \% \pm 7 \%$ & $32 \% \pm 6 \%$ & .42 \\
\hline$\geq 5 \%$ decrease in $\mathrm{RVFAC}^{*}$ & $15 / 55(27 \%)$ & $62 / 170(36 \%)$ & .21 & $25 / 59(42 \%)$ & $57 / 177(32 \%)$ & .16 \\
\hline
\end{tabular}

Data represent mean \pm standard deviation or $\mathrm{n}(\%)$ as appropriate. $A I$, Aortic index; $A A o$, ascending aorta; $D I$, distensibility index; RVFAC, right ventricular fractional area change. *Between Glenn and 14-mo echocardiogram. 